\title{
Entropy Application for Forecasting
}

\author{
Ana Jesús López-Menéndez * and Rigoberto Pérez-Suárez \\ Department of Applied Economics, University of Oviedo, Campus del Cristo s/n, 33006 Oviedo, Asturias, Spain; \\ rigo@uniovi.es \\ * Correspondence: anaj@uniovi.es
}

Received: 19 May 2020; Accepted: 27 May 2020; Published: 29 May 2020

Keywords: information theory; uncertainty; forecasting methods; forecasting evaluation; accuracy; M-competition; combined forecasts; scenarios

The information theory developed by Shannon [1] defines the entropy for any probabilistic system as a measure of the related uncertainty. This measure, inspired by the entropy defined in thermodynamics by Boltzmann [2], provides a link between uncertainty and probability and opens a wide variety of applications in different fields.

The basic idea of information theory is that the informational content of a message depends on the degree to which it is surprising: if an event is very likely to occur, there is no surprise when this event happens as expected; on the contrary, it is much more informative to know that an unlikely event has taken place.

In this context, entropy can be understood as a measure of unpredictability and therefore it is not surprising that entropy and information theory can be of great help in a broad range of problems related to forecasting, as shown by Theil $[3,4]$.

The contributions to this Special Issue "Entropy Application for Forecasting" show the enormous potential of entropy and information theory in forecasting, including both theoretical developments and empirical applications.

The contents cover a great diversity of topics, such as the aggregation and combination of individual forecasts [5,6], the comparison of forecasting performances $[7,8]$, the analysis of forecasting uncertainty [9], robustness [10] and inconsistency [11], and the proposal of new forecasting approaches [12-14].

A great diversity is also observed in the methods, since the contributions encompass a wide variety of time series techniques (ARIMA, VAR, State Space Models, etc.) as well as econometric methods and machine learning algorithms.

Furthermore, the empiric contents are also diverse including both simulated experiments and real-world applications. More specifically, the contributions provide empirical evidence that refer to the economic growth and gross domestic product (GDP) [5,9], the M4 competition dataset [8], the confidence and industrial trend surveys [9], and some stock exchange composite indices (Taiwan, Shanghai, Hong-Kong) [11], as well as other real data from a Portuguese retailer [7] and a Chinese grid company [12].

In summary, this Special Issue provides an engaging insight into entropy applications for forecasting, offering an interesting overview of the current situation and suggesting possibilities for further research in this field.

Acknowledgments: We want to express our thanks to the authors of the contributions of this Special Issue, and to the journal referees for their valuable comments and suggestions. We also acknowledge the confidence of the journal Entropy and its support in the development of this Special Issue.

Conflicts of Interest: The authors declare no conflict of interest. 


\section{References}

1. Shannon, C.E. A Mathematical Theory of Communication. Bell Syst. Tech. J. 1948, 27, 379-423. [CrossRef]

2. Boltzmann, L. Über die Mechanische Bedeutung des Zweiten Hauptsatzes der Wärmetheorie. Wien. Ber. 1866, 53, 195-220.

3. Theil, H. Applied Economic Forecasting; North Holland Publishing: Amsterdam, The Netherlands, 1966.

4. Theil, H. Economics and Information Theory; North Holland Publishing: Amsterdam, The Netherlands, 1967.

5. Bretó, C.; Espinosa, P.; Hernández, P.; Pavía, J.M. An Entropy-Based Machine Learning Algorithm for Combining Macroeconomic Forecasts. Entropy 2019, 21, 1015. [CrossRef]

6. Fernández-Vázquez, E.; Moreno, B.; Hewings, G. A Data-Weighted Prior Estimator for Forecast Combination. Entropy 2019, 21, 429. [CrossRef]

7. Oliveira, J.M.; Ramos, P. Assessing the Performance of Hierarchical Forecasting Methods on the Retail Sector. Entropy 2019, 21, 436. [CrossRef]

8. Ponce-Flores, M.; Frausto-Solís, J.; Santamaria-Bonfil, G.; Pérez-Ortega, J.; González-Barbosa, J.J. Time Series Complexities and Their Relationship to Forecasting Performance. Entropy 2020, 22, 89. [CrossRef]

9. López-Menéndez, A.J.; Pérez-Suárez, R. Acknowledging Uncertainty in Economic Forecasting. Some Insight from Confidence and Industrial Trend Surveys. Entropy 2019, 21, 413. [CrossRef]

10. Mei, W.; Liu, Z.; Su, L.; Du, L.; Huang, J. Evolved-Cooperative. Entropy 2019, 21, 912. [CrossRef]

11. Guan, H.; Dai, Z.; Guan, S.; Zhao, A. A Neutrosophic Forecasting Model for Time Series Based on First-Order State and Information Entropy of High-Order Fluctuation. Entropy 2019, 21, 455. [CrossRef]

12. Lei, M.; Ming, S.; Yu, S. Demand Forecasting Approaches Based on Associated Relationships for Multiple Products. Entropy 2019, 21, 874. [CrossRef]

13. Vanhoucke, M.; Batselier, J. A Statistical Method for Estimating Activity Uncertainty Parameters to Improve Project Forecasting. Entropy 2019, 21, 952. [CrossRef]

14. Popkov, Y.S. Soft Randomized Machine Learning Procedure for Modeling Dynamic Interaction of Regional Systems. Entropy 2019, 21, 424. [CrossRef]

(C) 2020 by the authors. Licensee MDPI, Basel, Switzerland. This article is an open access article distributed under the terms and conditions of the Creative Commons Attribution (CC BY) license (http://creativecommons.org/licenses/by/4.0/). 